\title{
Vestígios Do Ensino De Desenho Na Escola Normal Do Maranhão: Uma Leitura A Partir De Revisão De Literatura
}

\author{
Des Traces D’enseignement Du Dessin Dans L'ecole Normale Du Maranhão: Une \\ Lecture Basée Sur Une Revue De Littérature
}

\author{
Marcos Denilson Guimarães* \\ Universidade Federal do Maranhão - (UFMA) \\ Maria Consuelo Alves Lima** \\ Universidade Federal do Maranhão - (UFMA)
}

\begin{abstract}
Resumo
Buscou-se neste artigo identificar nos trabalhos já produzidos de história da educação do Maranhão vestígios e/ou pistas (Bloch, 2002) que evidenciassem como se deu a formação de professores primários em Desenho na Escola Normal desse Estado. Com vistas a atingir esse objetivo, foi feita uma breve revisão da literatura, a partir da qual se estabeleceu a investigação. Neste sentido, descreve-se o movimento social, político e educacional da Escola Normal do Maranhão dos oitocentos (Saldanha, 2008; Soares, 2016; Castro, 2018), incluindo as tentativas de institucionalização e situando as condições que possibilitaram a formação dos profissionais no tocante à disciplina Desenho. A partir da tentativa de inserir o Maranhão num contexto de modernidade e progresso, a disciplina Desenho se insere neste movimento de alterações na formação dos professores primários maranhenses. E embora constitua um estudo ainda inicial, nomes de professores de Desenho e as suas devidas nomenclaturas já podem indicar dois possíveis movimentos: um de tomada desses sujeitos como experts em educação (Hofstetter et al., 2017) e outro de finalidades (Chervel, 1990) desta disciplina escolar.
\end{abstract}

Palavras-chave: Desenho, Escola Normal, História da Educação Matemática.

\section{Resumè}

On a cherché dans cet article identifier dans les travaux produit par l'histoire de l'éducation du Maranhão les traces et/ou pistes (Bloch, 2002) qui montrent comment les enseignants du primaire ont été formés en Dessin dans l'École Normal de cet État. En vue d'atteindre cet objectif,on a fait une brève revue de la littérature basée sur ce qui est établi pour la recherche. En ce sens, on a décri le mouvement social, politique et éducatif de l'Ecole Normal du Maranhão des années quatre-vingt du XIX siècle (Saldanha, 2008; Soares, 2016; Castro, 2018), est inclus, y compris les tentatives d'institutionnalisation et les conditions permettant de former des professionnels. en ce qui concerne à la discipline Desenho. A partir d'essayer d'insérer le Maranhão dans un contexte de modernité et de progrès, la discipline Desenho sera

\footnotetext{
* Doutor em Ciências pela Univeridade Federal de São Paulo (UNIFESP). Pós-doutorando bolsista CAPES/BRASIL no âmbito do Programa Nacional de Cooperação Acadêmica da Universidade Federal do Maranhão (PROCAD/Amazônia), processo no. 88887-358325/2019-00, São Luís, Maranhão, Brasil. E-mail: markito_mat@hotmail.com.

** Doutora em Física pela Universidade Federal do Ceará. Professora do Departamento de Física e do Programa de Pós-graduação em Ensino de Ciências e Matemática (PPECEM) da Universidade Federal do Maranhão (UFMA). Estudo no âmbito do Programa Nacional de Cooperação Acadêmica na Amazônia PROCAD/Amazônia, processo nº 88881.199848/2018-01 - CAPES, São Luís, Maranhão, Brasil. E-mail: mconsuelo@ufma.br.
} 
insérée dans ce mouvement de changements dans la formation des instituteurs maranhenses. Malgré une étude initiale, les noms des professeurs de Dessin et leur nomenclature déjá indiquent mouvements possibles: l'un de faire ces personnages comme experts en éducation (Hofstetter et al., 2017) et une autre de finalités (Chervel, 1990) de cette discipline scolaire.

Mots-clés: Dessin, École Normale, Historie de l’Éducation Mathématiques.

\section{Considerações Iniciais}

No sentido de aprimorar a formação de pessoal e o desenvolvimento das pesquisas nas pós-graduações da Região Amazônica, diminuindo as assimetrias entre as outras regiões do país, propôs-se o desenvolvimento de um projeto de ensino e de pesquisa na área de Ensino de Ciências e Matemática, inserido no Programa Nacional de Cooperação Acadêmica na Amazônia (PROCAD/Amazônia). As três instituições envolvidas, a Universidade Federal do Maranhão (UFMA), a Universidade Federal do Amazonas (UFAM) e a Universidade Federal de Santa Catarina (UFSC), se associaram a partir dos Programas de Pós-graduação em Ensino de Ciências e Matemática, da UFMA e da UFAM, e do Programa de Pós-graduação em Educação Científica e Tecnológica, da UFSC, com o objetivo de promover a consolidação dos Programas das duas instituições da Região Amazônica, propondo, entre outros objetivos específicos, criar novas linhas de pesquisa nessas pós-graduações e promover melhorias na quantidade e na qualidade das produções científicas e nas dissertações dos grupos envolvidos.

Alinhado a esse projeto de âmbito maior, que tem como um dos objetivos criar a linha de pesquisa no campo da Epistemologia e História da Ciência e da Matemática, um projeto de pós-doutorado foi submetido pelo primeiro autor deste trabalho e, após apreciado por uma comissão julgadora, passou a ser desenvolvido integrado ao Programa de Pós-Graduação em Ensino de Ciências e Matemática (PPECEM) da Universidade Federal do Maranhão (UFMA), pelo Edital n $n^{\circ}$. 01/2019. O projeto intitulado História da Educação Matemática e a formação de professores primários de Desenho na Escola Normal de São Luís (1890-1939) tem como objetivo geral produzir uma história da educação matemática a partir da Escola Normal de São Luís (Maranhão), com vistas analisar o processo de formação de professores primários de Desenho, entre os anos de 1890 e $1939^{1}$.

\footnotetext{
${ }^{1}$ A escolha desse marco cronológico se deve ao fato de que, após algumas tentativas frustradas de implantação de um curso destinado à formação de professores primários na capital, em 1890 tem-se a efetiva criação de uma Escola Normal a partir do Decreto n. 21 de 15 de abril de 1890. Já o ano de 1939 fica por conta da data de extinção da Escola Normal que passou a ser chamada de Instituto de Educação do Maranhão, ato colocado em prática pelo Decreto-Lei Estadual $n^{\circ}$. 186. Permaneceu em funcionamento até o ano de 1973 quando por meio do Decreto-lei Estadual nº 5.094 de 10 de agosto de 1973 houve a sua extinção (Melo, 2009; 2012; 2015).
} 
A escolha do Desenho como tema de pesquisa vem dos estudos já desenvolvidos pelo primeiro autor deste trabalho no doutorado. Naquela ocasião, foi elaborada uma pesquisa que buscou investigar, em perspectiva histórica, as transformações que sofreram as finalidades do ensino do Desenho no curso primário de São Paulo, dentro do marco cronológico de 1829 a 1950. Financiada em sua grande parte pela Fundação de Amparo à Pesquisa do Estado de São Paulo (FAPESP), evidenciou, como resultados, transformações nas finalidades do ensino de Desenho as quais estavam atreladas à uma concepção dual de ensino desse saber. O par elementar/rudimentar ligava-se, respectivamente, à uma concepção racionalista de valorização das ideias e do saber na qual o ensino do Desenho servia de acesso a saberes mais elaborados, cuja aprendizagem de conceitos abstratos e teóricos aproximava o desenho da Geometria. Por outro lado, a partir do início do século XX, o saber Desenho ganha autonomia da Geometria e passa a ser visto como uma base de rudimentos, com articulação com a vida cotidiana e prática de seus alunos.

Um passo seguinte, dando continuidade a esse estudo, pensou-se em verificar como se deu a formação destes professores primários em Desenho nas escolas destinadas à sua preparação. Foi então, assim, que surgiu a ideia de propor a escrita deste artigo, o qual vinculase ao referido projeto.

Dessa maneira, na tentativa de evidenciar as primeiras aproximações com a temática em questão e visando executar uma das etapas do citado projeto que é o levantamento de trabalhos produzidos anteriormente no Estado, que possam ser caracterizados como de história da educação ou de história da educação matemática, foi feito um primeiro trabalho de mapeamento de artigos, dissertações, teses e livros que apontassem referências tanto sobre a Escola Normal quanto sobre a formação de professores de Desenho nessa escola. Tendo em vista que até o momento não se tem notícias de um estudo exclusivo que problematize este objeto de pesquisa, nesta empreitada de revisão de literatura, buscou-se captar, nas fontes encontradas, vestígios a respeito da formação de professores de Desenho na Escola Normal deste Estado, que sinalize possíveis pistas e encaminhamentos de como eram formados esses docentes.

O termo vestígios, aqui utilizado, é uma referência ao trabalho de Marc Bloch (2002) em seu destacado livro "Apologia da História ou o Ofício de Historiador", no qual afirma que só conhecemos os fatos humanos do passado, a maior parte deles no presente, através de vestígios. São esses traços deixados no presente pelo passado que, mediante crítica aos documentos e suas regras, constituirão os chamados fatos históricos. Sendo o passado um dado que nada mais modificará, cabe ao historiador entender que o conhecimento do passado é algo 
em progresso e que se dá incessantemente pela transformação e aperfeiçoamento de suas análises. Os documentos, "mesmo os aparentemente mais claros e mais complacentes" (Bloch, 2002, p. 79) postos pelo passado à disposição dos historiadores, só dizem algo quando sabemos interrogá-los.

Uma das discussões importantes lançada no livro de Bloch (2002) refere-se aos tipos de documentos e seus empregos específicos. Para ele, reunir documentos que se estimam necessários para uma pesquisa é uma das tarefas mais difíceis do historiador. Em sua opinião, não é possível fazer história utilizando-se de apenas um tipo de documentação, pois

[...] se quase todo problema humano importante pede assim o manejo de testemunhos de tipos opostos, é, ao contrário, de absoluta necessidade que as técnicas eruditas se distingam por tipos de testemunhos. [...] É bom, a meu ver, é indispensável que o historiador possua ao menos um verniz de todas as principais técnicas de seu ofício. Mesmo apenas a fim de saber avaliar, previamente, a força da ferramenta e as dificuldades de seu manejo (Bloch, 2002, p. 81).

$\mathrm{Na}$ verdade, quando um historiador supõe os fatos como algo já dado a priori, estaria ele completamente enganado. Além de permitir um aprendizado diferente para o tipo de escolha feita, utilizar outros documentos permite ao historiador um enorme ganho em termos de aprofundamento da pesquisa, bem como tem-se aí a possibilidade de evidenciar as finalidades tanto reais quanto de objetivo de uma determinada matéria escolar (Chervel, 1990). Assim, futuramente, os documentos que reunirei para responder ao objetivo geral desta pesquisa serão os documentos oficiais normativos (leis, decretos, regulamentos etc.) como revistas pedagógicas, manuais e livros didáticos, cadernos e provas escolares elaborados e/ou publicados no referido Estado.

Bloch (2002) alerta para o fato de que não ter um itinerário de questões previamente estabelecidas para o questionamento dos fatos, "implicaria o risco de errar eternamente ao acaso" (Bloch, 2002, p. 79). Em síntese, seria uma grande ilusão imaginar que a produção em história e, consequentemente, em história da educação matemática, se faça sem questões postas pelo historiador. Neste sentido, para o alcance do objetivo visado, intenta-se inicialmente responder algumas questões: qual o primeiro professor de Desenho da Escola Normal do Maranhão? E qual o primeiro manual adotado por ele? Quais os saberes responsáveis pela formação desse professor no tocante à matéria de Desenho? Quem foram os experts ${ }^{2}$

\footnotetext{
2 De acordo com autores suíços, o termo expertise designa “[...] uma instância, em princípio reconhecida como legítima, atribuída a um ou a vários especialistas - supostamente distinguidos pelos seus conhecimentos, atitudes, experiências -, a fim de examinar uma situação, de avaliar um fenômeno, de constatar fatos" (Hofstetter \& Schneuwly, 2017, p. 57). O expert é, portanto, o sujeito que pratica essa ação. Aquele que se envolve diretamente com a sistematização de novos saberes para o campo pedagógico a partir de uma convocatória do Estado.
} 
maranhenses responsáveis pelo encaminhamento de propostas educacionais referentes à formação de professores primários de Desenho e como se posicionavam diante destas questões? Deste modo, eis aqui um primeiro ensaio.

\section{O Nascimento Da República Maranhense E Suas Políticas Educacionais}

A delimitação da última década do século XIX como marco inicial desta pesquisa devese ao fato de se constituir num período de transição do sistema imperial para o republicano, no qual pôde-se observar "em nível de discurso político a intenção de construir um projeto modernizador para o Maranhão" (Saldanha, 2008, p. 58). Mais do que isso, a formação de novas alianças locais de grupos e partidos políticos denotava o começo de um forte processo de reorganização oligárquica que culminaria com o surgimento de "novas bandeiras de luta e entre elas estava a de expandir o ensino. O tema da educação popular passou a frequentar [sic] mais assiduamente o discurso político e a educação a ser proclamada remédio para todos os males que afligiam a nação" (Saldanha, 2008, p. 16). Em consequência disto, o ensino começou a ser reorganizado e seus sintomas logo se fizeram presentes nas várias e sucessivas reformas que atingiram a instrução pública dos Estados. No caso do Maranhão, embora a maioria delas fossem motivadas por interesses políticos e visassem beneficiar sobretudo as camadas mais abastadas da sociedade maranhense, estiveram em pauta alguns empreendimentos importantes tais como as primeiras tentativas de reorganizar e reformar a Instrução Pública, criar uma Escola Normal e uma Escola Modelo na capital, reformar a Magistratura, criar uma Biblioteca Pública etc. (Saldanha, 2008).

Até o final do século XIX, no Maranhão, a estrutura escolar da sociedade baseava-se numa estrutura excludente, baseada no modelo patrimonialista que impedia os integrantes das camadas populares de considerar a escola e a aquisição cultural letrada um direito seu. $\mathrm{O}$ processo de intelectualização da classe dominante estava fundamentado num ensino bacharelesco, enciclopédico e acadêmico, reservado para a elite e classe média, que viam na escola um meio de concretização de seus próprios interesses. Com esse ambiente polarizado, as lutas pela expansão e democratização da educação foram viabilizadas pelos "princípios liberais que atribuíam à educação um papel social fundamental para o progresso do indivíduo e da nação" (Saldanha, 2008, p. 71). A escola deveria, portanto, deixar de ser privilégio da elite, basear-se no mérito e não na riqueza da minoria. Com isso "O despertar do sentimento nacional, que se iniciou com a Proclamação da República, trouxe o desejo de se construir um país mais 
moderno e democrático, capaz de proporcionar uma maior participação popular na vida político-econômica da Nação" (Saldanha, 2008, p. 72-73).

\section{As Tentativas De Institucionalização De Uma Escola Normal Na Capital Maranhense}

Segundo Saviani (2009), a necessidade de formação docente no Brasil emerge de forma explícita após a Proclamação da República em 1822 quando se cogitou a possibilidade de organizar nossa instrução pública. Para ele, entre o período de 1827 e 1890 houve ensaios intermitentes de formação de professores cuja preocupação não era somente de ensinar as primeiras letras, mas de preparar os docentes no domínio do método de ensino mútuo. Para Tanuri (2000), essa foi realmente a primeira forma exclusivamente prática de preparação de professores.

Na lista de criação de Escolas Normais elaborada por Saviani (2009), Maranhão aparece como o décimo sexto Estado a ter instalada em sua capital uma Escola Normal, em 1890. A primeira delas foi criada em Niterói, em 1835. Já na pesquisa realizada por Tanuri (2000), diferente da de Saviani (2000), a autora registrou que no Maranhão o processo de instalação começou em 1874 com a criação de uma escola normal particular, subvencionada pelo governo. Percebe-se então que as mudanças que vinham surgindo no resto do país não chegaram tão imediatamente na Província do Maranhão.

Inserido no desejo de reconstrução de um país mais moderno, o Maranhão teve a criação e instalação definitiva de uma Escola Normal na Capital, por meio da Reforma de 1890, que reorganizou o ensino público do Estado. Todavia, como alertou Tanuri (2000), antes disso, houve duas tentativas (uma pública e outra privada) frustradas de preparação e formação específicas do professor primário. A primeira delas ocorreu, em 1839, "quando o Governo da Província enviou à França o jovem Felipe Benício Conduru, que deveria especializar-se no método de Lancaster ou método do 'ensino mútuo ${ }^{3, "}$ (Saldanha, 2008, p. 111). Já em 1840, instalou-se em uma das salas do Convento do Carmo uma aula de Pedagogia, a qual foi entendida e denominada na época de "Escola Normal". O governo passou então a exigir a frequência obrigatória dos professores primários “os quais deveriam depois utilizar-se desse

\footnotetext{
${ }^{3} \mathrm{O}$ método de ensino monitorial ou mútuo foi adotado na França no ano de 1815 e no Brasil foi instituído oficialmente pelo Decreto das Escolas de Primeiras Letras, de 15 de outubro de 1927. Tal método nasceu com o processo de industrialização, cuja função era transmitir rapidamente e com poucos gastos a todos os alunos os saberes e o saber-fazer indispensável àquele momento. Baseava-se num ensino compartilhado entre professor e monitores. Esses monitores - alunos mestres - eram os responsáveis pelo ensino dos outros alunos, exercendo a função de monitoria. O papel do professor se resumia a inspeção (Bastos, 2018).
} 
método nas escolas em que lecionava" (Saldanha, 2008, p. 112). Porém, muitos professores recusaram-se a frequentá-la, alegando serem contrários à proposta de adoção do método francês utilizado, o método lancasteriano de ensino, afirmando sê-lo um agravante à qualidade já precária do ensino. Para Castro (2018), mesmo com esses notórios agravantes, o funcionamento da Escola Normal como instituição de ensino na província, acabou contribuindo para a adoção e/ou expansão deste método no Estado. E que, para Felipe Condurú, as disciplinas escolares em que os professores deveriam centrar seus esforços eram a leitura, a escrita e a aritmética, com especial atenção para a geografia e a língua portuguesa (Castro, 2018). Como se vê, Desenho não era uma disciplina ainda de relevância para a formação do professor primário. Assim, em 1844, já não havia quem quisesse se matricular para essa aula, forçando o então presidente da Província a propor o seu fechamento, sendo efetivamente "desligada do Liceu e transformada em escola de primeiras letras" (Saldanha, 2008, p. 113).

Sob os cuidados de Antônio Oliveira e Antônio Coqueiro (Castro, 2018), a segunda tentativa de implantar um curso destinado à formação de professores primários deu-se em 1870 com a fundação da Sociedade Onze de Agosto, entidade particular formada por um grupo de intelectuais reconhecidos da sociedade pelos "objetivos educacionais e beneficentes, e entre eles incluía o oferecimento de cursos noturnos gratuitos para os operários da capital" (Saldanha, 2008, p. 113). No currículo desse curso estavam algumas cadeiras do ensino secundário e a existência de uma única disciplina voltada para a formação pedagógica denominada "Curso de Moral, Doutrina Cristã e Pedagogia". Conforme documento de criação do Curso Normal - Lei Provincial n. 1088 de 17 de julho de 1874 - o professor regente da cadeira de Desenho Linear Aplicado às Artes e Desenho Linear e lavis aplicado às Artes, ofertada nos dois anos de curso, era Agostinho Autran (Soares, 2016; Castro, 2018). Dos 449 alunos matriculados no ano de 1874, 24 frequentavam a aula de Desenho (Castro, 2018).

Soares (2016), em seu trabalho sobre o ensino de matemática, não considerou o Desenho Linear como uma disciplina desta área. Desse modo, questiona-se: por que o ensino de Desenho Linear não era visto por esta autora como uma disciplina de formação matemática para formar o professor primário, enquanto Aritmética e Geometria eram? O que ela nos informa é que o ensino dessas duas disciplinas não envolvia o ensino mútuo e que assim "as lições eram transmitidas em tempo pré-determinado, os conteúdos eram sequenciados do mais fácil para o mais difícil e as lições eram transmitidas pausadamente, dando tempo para que os alunos escrevessem, o que o professor ditava" (Soares, 2016, p. 07). Os programas desse dito curso Normal da Sociedade Onze de Agosto foram aprovados no mesmo ano (1870), no entanto, o 
curso encerrou-se sem conseguir diplomar nenhum professor, vindo, oito ano depois, fechar definitivamente as suas atividades (Saldanha, 2008) devido à falta de alunos e pelas dívidas contraídas pela instituição desde a sua criação (Castro, 2018). Ao que tudo indica, a referência feita por Tanuri (2000) baseava-se nessa última tentativa.

Destinada a ambos os sexos, a oficialização da criação da primeira Escola Normal do Maranhão só aconteceu 55 anos depois da criação da primeira Escola Normal brasileira proclamada no governo de José Tomás Porciúncula, pelo Decreto nº 21 , de 15 de abril de 1890, que reorganizou o ensino público do Estado que, de fato, tornou oficial a sua criação. Para Saviani (2009), o ano de 1890 era o início da fase de estabelecimento e expansão dessas escolas, impulsionadas pela reforma de instrução pública do estado de São Paulo. Anexada ao Liceu, inicialmente, começou a funcionar com 10 cadeiras, dentre elas, as de Aritmética, Álgebra, Geometria e Trigonometria ( $\left.2^{\mathrm{a}}\right)$, Pedagogia $\left(7^{\mathrm{a}}\right)$ e Desenho $\left(8^{\mathrm{a}}\right)$. Na lista das cadeiras, constava que as seis primeiras eram comuns aos dois cursos (Saldanha, 2008).

\section{A Presença Do Desenho Na Escola Normal Maranhense: O Que Dizem Os Trabalhos Já Produzidos?}

Em particular, o curso da Escola Normal naquela época (final do século XIX) tinha duração de 3 anos. Com um currículo mais extenso que o de 1874, o curso possuía como finalidade instruir os alunos professores e "exercital-os na maneira prática de ensinar, educando-os na methodologia peculiar a cada uma das disciplinas" (Saldanha, 2008, p. 116). Nas palavras de Soares (2016, p. 07), objetivava "fornecer ao professor normalista uma formação geral para o seu ensino".

No sentido de agilizar seu funcionamento, o então governador do Estado dispensou a elaboração de concurso e nomeou interinamente os professores Luis Medeiros e Cândido Jorge Barbosa para as cadeiras de Música e Desenho, respectivamente. Já a cadeira de Pedagogia foi assumida pelo Agripino Azevedo, que já era lente do Liceu. A escola deveria funcionar no prédio do Convento do Carmo, onde funcionara o Liceu (escola destinada à elite econômica local). No entanto, como houve atraso no início de seu funcionamento "a instalação fez-se no prédio alugado à Rua Formosa $\mathrm{n}^{\mathrm{o}} 28$, para onde se transferira desde maio do mesmo ano, o Liceu" (Saldanha, 2008, p. 116).

Pelo que foi posto anteriormente, é possível afirmar que, diferentemente do nome que aparece em 1874, o primeiro professor de Desenho da recém-criada Escola Normal foi Cândido Jorge Barbosa. Outra informação importante trazida pela autora é a de que "os professores de 
Pedagogia, Desenho, Música e Ginástica, tal qual a professora de Costuras e Bordados, seriam remunerados com $800 \$ 000$ réis anuais, quantia inferior aos vencimentos estabelecidos para os professores primários, [...]" (Saldanha, 2008, p. 115) e "bem inferior aos do Liceu Maranhense" (Salomão, 2015, p. 60). Segundo Saldanha (2008), isso demonstrava que essas disciplinas não eram valorizadas, tornando os seus ensinos algo meramente secundário. Ademais, tece comentários a respeito da fragilidade e deficiência do currículo visto que apenas a disciplina de Pedagogia achava-se voltada à formação especial do profissional de ensino. De todo modo, como consta no trabalho de Lima (2014), no Regulamento desta escola criado pelo supracitado decreto, Desenho era uma das dezessete disciplinas a serem ministradas. Neste caso, na lista informada, ocupava o $14^{\circ}$ lugar. Ademais, afirma que "o livro $O$ Maranhão contemplava todos os temas prescritos pelos conteúdos curriculares previstos pelo programa de ensino da Escola Normal" (Lima, 2014, p. 87, grifos do autor). Poder-se-ia, então, considerar esse livro como o primeiro manual também adotado para o ensino de Desenho?

Desde sua instalação e funcionamento, a Escola Normal passou por algumas dificuldades, tanto de ordem pessoal, econômica quanto pedagógica. Como bem assinala Saldanha (2008, p. 63), o fato de não ter tido uma frequência esperada (procura e matrículas efetuadas) houve momentos em que, "se pensou em extingui-la, visto que onerava os cofres públicos e não conseguira formar, até 1895, senão quatro professoras". Algo ainda mais agravante continuava sendo o desprestígio "a que era relegado o magistério primário". Para Tanuri (2000, p. 65) isso era reflexo sobretudo da "falta de interesse da população pela profissão docente, acarretada pelos minguados atrativos financeiros que o magistério primário oferecia e pelo pouco apreço de que gozava".

O currículo com que a escola iniciou seu funcionamento foi determinado pelo Regulamento de 22 de junho de 1890 . No $1^{\circ}$ ano estava previsto o ensino do Desenho de imitação e Desenho Linear; no $2^{\circ}$ ano, apenas Desenho Linear; no $3^{\circ}$ ano, Elementos de Geometria Descritiva e Desenho Linear e Desenho de imitação. De acordo com Saldanha (2008), este currículo apresentava "um cunho mais cientificista que literário, [...]. No mais,

Ao lado das disciplinas científicas, que demonstram a influência do positivismo, podem ser encontradas aquelas relacionadas aos estudos sociais e ao estudo das artes, e, finalmente, a Pedagogia, única disciplina voltada especificamente para a habilitação técnico-pedagógica (Saldanha, 2008, p. 117-118).

Sobre as disciplinas da área das Ciências Exatas, a autora aponta que os programas destinados à Escola Normal eram bastante simplificados em seus conteúdos. Em sua opinião, isso ocorria pelo simples fato de que os dois cursos tinham objetivos distintos. 
Com a intenção de "adequar o quadro institucional brasileiro ao novo regime político e à nova Carta Constitucional" (Saldanha, 2008, p. 80) surgem então outras reformas. O Decreto n. 94 de $1^{\circ}$ de setembro de 1891, elaborado por Lourenço de Sá, dá nova organização à instrução pública maranhense. De caráter obrigatório, livre, gratuito e laico, teve-se a tentativa de municipalizar o ensino primário. Para Saldanha (2008), o Estado procurava se eximir dos encargos com o ensino elementar, relegado às pessoas das camadas subalternas. Seu interesse era promover o ensino secundário. Esta reforma apesar de manter a organização do ensino primário constituído por escolas de $1^{\circ}, 2^{\circ}$ e $3^{\circ}$ graus, não fazia nenhuma referência ao Ensino Técnico. Extinguiu algumas cadeiras do Liceu, o que gerou grande polêmica.

Consta neste Decreto que o curso da Escola Normal estava dividido em 3 anos com a presença de Geometria prática e desenho linear e Desenho de imitação nos $1^{\circ}$ e $2^{\circ}$ anos e apenas Desenho de imitação no $3^{\circ}$. Pela análise desse Decreto é possível afirmar que o Desenho de imitação é a única matéria ensinada durante os três anos. Todavia, algumas questões precisam ainda ser respondidas: por que o Desenho de imitação ganhou tanto espaço nesta formação de professores? Quais os livros e/ou manuais didáticos adotados para o seu ensino? Quais os professores responsáveis pelo seu ensino? Que finalidades tinha? Vigorando por apenas quatro meses, o regulamento elaborado no governo José Tomás Porciúncula voltou a funcionar até o ano de 1893.

Uma nova lei de instrução é instaurada no ano de 1893 na qual o ensino ficava dividido em primário, normal, secundário, profissional ou técnico e superior. A Lei n. 56, de 15 de maio de 1893, aprovada no governo de Cunha Martins, tenta mesclar algumas medidas propostas pela Lei de 1890 com outras contidas na extinta Reforma de Lourenço de Sá e "trouxe como medida mais importante a determinação de providenciar a equiparação do Liceu Maranhense ao Ginásio Nacional" (Saldanha, 2008, p. 89-90). No entanto, a organização do ensino primário e normal irá ser modificada pela reforma de 1895 de Benedito Leite. Influenciado pelas ideias liberais que concebiam a educação como a solução de todas as mazelas sociais, esse fervoroso ator social lutou pela revitalização da Escola Normal posicionando-se "firmemente contra as tentativas de extingui-la" (Saldanha, 2008, p. 90). Pensada para solucionar o problema de funcionamento da Escola Normal, essa reforma teve ainda o caráter de "valorizar o professor normalista e impedir a extinção do curso" (Saldanha, 2008, p. 18). Acusada de onerar os cofres públicos sem produzir os frutos esperados, a Escola Normal passou ter a sua frente a figura importante de Benedito Leite ${ }^{4}$ o qual considerava que era preciso ir até às raízes do problema,

\footnotetext{
${ }^{4}$ Para mais informações sobre ver Licar (2010).
} 
"que se achavam ligadas à legislação obsoleta que regulamentava o provimento das cadeiras do ensino público" (Saldanha, 2008, p. 91), e mudar as leis vigentes era o caminho mais viável para a revitalização do ensino normal.

Benedito Leite, por meio da Lei 9.119 de maio de 1895, propôs o aumento dos vencimentos dos professores - que passaram a receber $150 \$ 000$ réis mensais - e a renovação do corpo docente, achando ele que isso possibilitaria a substituição dos métodos tradicionais de ensino pelos mais modernos. De fato, sua pretensão era a valorização do professor primário habilitado. No entanto, em seus dez anos de funcionamento, apenas 11 alunos foram diplomados para exercer o magistério.

No ano de 1896 um novo Regulamento da Escola Normal é aprovado. Desta vez o problema de um currículo mais cientificista foi atenuado. Ficou assim definido para o caso de Desenho: $1^{\circ}$ ano ( 2 horas); $2^{\circ}$ ano ( 2 horas) e $3^{\circ}$ ano (apenas 1 hora). As atividades escolares começavam às oito horas da manhã e encerravam-se às três horas da tarde. Em 1899, esse horário foi alterado: das 7 às 17 horas. Para fins avaliativos, o ensino de Desenho previa a realização de provas práticas. Um destaque especial na época para a "quase total inexistência de livros didáticos" (Saldanha, 2008, p. 125). Porém, apesar desse empecilho, houve por parte dos professores de Pedagogia a tentativa de elaboração de um compêndio que servisse para o uso dos normalistas. Será que para o ensino de Desenho também houve certa preocupação? Com quais livros e/ou manuais didáticos eles foram formados?

Como local de exercício de sua prática foi criada em 1896, por meio da lei $\mathrm{n}^{\circ} 155$, de maio de 1896, a Escola Modelo do Maranhão “destinada à educação de menores de ambos os sexos e a ser um campo de estágio para alunas normalistas" (Saldanha, 2008, p. 126). No entanto, somente em março de 1900 que iniciou seus trabalhos, "Dispondo de um corpo docente habilitado, de material didático e recursos sofisticados, de um currículo mais rico e complexo que as demais escolas, constituía-se numa instituição destinada à educação dos filhos das elites" (Saldanha, 2008, p. 127).

Em 1898, houve a separação do Liceu da Escola Normal por meio da Lei Estadual $n^{\circ}$ 207. Com isso, "a Escola Normal adquiriu maior autonomia e deixou de ser um simples apêndice do Liceu. Passou a ter seu próprio diretor, tendo sido designado para o cargo o nome respeitável do Dr. Almir Nina” (Saldanha, 2008, p. 128). 


\section{5 À Guisa Da Conclusão}

Como se pôde observar, a tentativa de inserir o Maranhão num contexto de modernidade e progresso levou muitos representantes da República a reacenderem a ideia de implantação definitiva de uma Escola Normal que pudesse ofertar aos interessados uma gama de estudos de caráter profissional, habilitando-os na preparação para atuarem junto às escolas primárias do Estado. Deste modo, para inseri-los numa "sociedade educativa global" (Castro, 2018, p. 110), fazia-se necessário e urgente que o ensino dado a esses futuros professores fosse baseado nos métodos, nas ideias e disciplinas que circulavam pelos países afora considerados desenvolvidos.

Acompanhando essa preocupação, a disciplina Desenho se insere neste movimento de alterações na formação dos professores primários maranhenses. Essa disciplina, desde a sua implantação no currículo escolar da Escola Normal, no ano de 1874, durante a vigência da Sociedade Onze de Agosto, foi ganhando cada vez mais espaço nos currículos de formação de professores atestando o entendimento de sua importância para a sociedade daquela época. Embora ainda não se saiba como esse saber foi de fato ensinado, quais métodos e manuais didáticos foram utilizados no seu ensino, advogamos aqui a importância de considerar os possíveis nomes de professores de Desenho já levantados, como possíveis experts em educação, bem como as nomenclaturas usadas na época, as quais podem indicar caminhos sobre as finalidades desta disciplina.

Considera-se ainda que, no que diz respeito à relevância do Desenho na formação destes professores, tanto nas Ciências quanto na Matemática, exerceram papeis importantes na aquisição do conhecimento empírico dos fenômenos naturais. E, para a formação do professor, os resultados da produção científica sobre história da educação matemática revelam-se importantes por possibilitarem uma reflexão mais apurada sobre o atual estágio de seu ofício.

Por fim, a continuidade desta história a partir do cruzamento com outros documentos será motivo para outras escritas.

\section{Agradecimentos}

À CAPES/BRASIL pela concessão da bolsa de Pós-doutorado no âmbito do Programa Nacional de Cooperação Acadêmica da Universidade Federal do Maranhão (PROCAD/Amazônia), processo n. ${ }^{\text {o } 88887-358325 / 2019-00 . ~}$ 


\section{Referências}

Bastos, M. H. C. (2018). Signo da modernidade educacional: o método monitorial/mútuo no Brasil (1808-1854). In Castro, C. A. \& Castellanos, S. L. V. (Eds.), História da escola: métodos, disciplinas, currículos e espaços de leitura. (pp. 51-83). São Luís: EDUFMA; Café \& Lápis.

Bloch, M. (2002). Apologia da história: ou o oficio de historiador. Rio de Janeiro: Jorge Zahar Editor.

Castro, C. A. (2009). Leis e regulamentos da Instrução Pública no Maranhão Império (18351889). São Luís: EDUFMA.

Castro, C. A. (2018). Aprender para ensinar: a disciplina Pedagogia nas "Escolas Normais" maranhenses (1840-1930). In C. A. Castro, \& S. L. V, Castellanos (Eds.), História da escola: métodos, disciplinas, currículos e espaços de leitura. (pp. 85-103). São Luís: EDUFMA; Café \& Lápis.

Chervel, A. (1990). História das disciplinas escolares: reflexões sobre um campo de pesquisa. Teoria \& Educação, v. 2, 177-229.

Hofstetter, R. et al. (2017). Penetrar na verdade da escola para ter elementos concretos de sua avaliação - A irresistível institucionalização do expert em educação (século XIX e XX). Trad. Marcos Denilson Guimarães e Wagner Rodrigues Valente. In R. Hofstetter \& W. R. Valente (Eds.), Saberes em (trans)formação: tema central da formação de professores. (pp. 55-112). São Paulo: Editora Livraria da Física (Coleção Contextos da Ciência).

Licar, A. C. N. C. (2010). A questão de livros da escola Modelo Benedito Leite: cultura material escolar e poder disciplinar no Maranhão (1900-1911). (Dissertação de Mestrado em Educação). Universidade Federal do Maranhão, São Luís.

Lima, N. N. (2014). Uma contribuição para a história do livro didático maranhense: a obra $O$ Maranhão, de Fran Paxeco (1913-1923). (Dissertação de Mestrado em Educação. Universidade Federal do Maranhão, São Luís.

Melo, S. M. B. A. (2019). O Instituto de Educação do Maranhão (1939-1973). Recuperado de http://www.histedbr.fe.unicamp.br/acer_histedbr/seminario/seminario8/ files/YTcHsryD. pdf.

Melo, S. M. B. (2012). Percurso histórico da formação de professores para a escola primária no Maranhão: Império e República Velha. In Anais do IX Seminário Nacional de Estudos e Pesquisas "História, sociedade e educação no Brasil" (pp. 4741-456). João Pessoa, PB: Universidade Federal da Paraíba. Recuperado de histedbr.fe.unicamp.br/acer histedbr/seminario/seminario9/PDFs/8.09.pdf

Melo, S. M. B. A. (2015). Formação de professores: o Instituto de Educação do Maranhão (1939-1973). InterEspaço: Revista de Geografia e Interdisciplinaridade, v. 1(1), 126-141. 
Saldanha, L. L. (2008). A instrução pública maranhense na primeira década republicana. Imperatriz: Ética.

Salomão, K. (2015). O ensino de música no Maranhão (1860-1912): uma ênfase nos livros escolares de Domingos Thomaz Vellez Perdigão e Antonio Claro dos Reis Rayol. (Dissertação de Mestrado em Educação. Universidade Federal do Maranhão, São Luís.

Saviani, D. (2009). Formação de professores: aspectos históricos e teóricos do problema no contexto brasileiro. Revista Brasileira de Educação, v. 14(40), 143-155.

Soares, W. J. B. (2016, outubro-novembro). Formação de professores e o ensino de Matemática na cidade de São Luís Oitocentista: tentativas de criação de uma Escola Normal. In Anais do $3^{\circ}$ Encontro Nacional de Pesquisa em História da Educação Matemática. São Mateus, ES: Universidade Federal do Espírito Santo. Recuperado de eventos.ufes.br/enaphem/3enaphem/paper/viewFile/2028/71

Tanuri, L. M. (2000). História da formação de professores. Revista Brasileira de Educação, (14), 61-88.

Submetido em: 02/09/2019

Aceito em: 06/09/2019 